КОМБИНИРОВАННАЯ СИСТЕМА ТЯГИ И

БОКОВОЙ СТАБИЛИЗАЦИИ ДЛЯ

МАГНИТНОЛЕВИТАЦИОННОГО

TPAНСПОРТА

\author{
А. В. Соломин
}

Ростовский государственный университет

путей сообщения

(Ростов-на-Дону, Россия)

\title{
THE COMBINATION SYSTEM OF TRACTION \\ AND LATERAL STABILIZATION FOR MAGNETOGRAVITATIONAL TRANSPORT
}

\author{
A. V. Solomin \\ Rostov State Transport University \\ (Rostov-on-Don, Russia)
}

\begin{abstract}
Одним из наиболее перспективных и экологически чистых новых видов транспортных средств является высокоскоростной магнитнолевитационный транспорт, перемещающийся со скоростями порядка 500 км/час. На современном этапе развития общества в качестве основного вида электрических машин для высокоскоростного магнитнолевитационного транспорта целесообразно использовать линейные асинхронные двигатели (ЛАД) с продольно-поперечным магнитным потоком, которые являются комбинированными системами тяги и боковой стабилизации. Большое влияние на величины тягового и бокового усилий ЛАД c продольно-поперечным магнитным потоком оказывает характер распределения тока во втортоичном элементе, на который существенным образом влияет распределение магнитодвижущих сил (МДС) в воздушном зазоре машины. Предложена конструкция ЛАД с продольно-поперечным магнитным потоком для комбинированной системы тяги и боковой стабилизации магнитолевитационного транспорта, развивающая повышенные усилия боковой стабилизации за счет создания в поперечном направлении беззубцовых активных зон
\end{abstract}


индуктора, выполнено математическое моделирование МДС в зазоре тягового линейного двигателя данного типа. Для анализа приняты допушения о равномерности распределения магнитной индукции в воздушном зазоре в поперечном и синусоидальном характере ее изменения в продольном направлении. Это позволило разработать новую математическую модель распределения МДС в воздушном зазоре линейного асинхронного двигателя с продольно-поперечным магнитным потоком. Разработанная математическая модель для расчета МДС тяговой линейной машины позволит повысить точность расчета тяговых и стабилизирующих боковых усилий комбинированной системы для магнитнолевитационного транспорта, в том числе и при различном взаимном расположении индуктора относительно вторичного элемента.

Для анализа характера распределения магнитодвижущей силы линейного асинхронного двигателя с продольнопоперечным магнитным потоком приняты допущения: магнитная проницаемость магнитопровода равна бесконечности; электрическая проводимость магнитопровода равна нулю; ток индуктора сосредоточен в бесконечно тонком слое на поверхности зубцов, обращенных ко вторичному элементу; ток индуктора создает в направлении оси « $x »$ синусоидально бегущую волну МДС; составляющие плотности тока по оси «у»» в индукторе и вторичном элементе равны нулю.

Для исследуемого варианта конструкции линейного асинхронного двигателя с продольно-поперечным магнитным потоком в соответствии с расчетными моделями и с учетом принятых при анализе допущений определены значения магнитодвижущих сил для всех рассматриваемых $2430 \mathrm{~s}$ поперечном направлении.

Установлено, что МДС в воздушном зазоре рассматриваемого линейного асинхронного двигателя с продольно-поперечным магнитным потоком представляет собой периодическую функцию с периодом $T_{x}=l$ по оси « $x$ в продольном и с периодом $T_{z}=2 L$ по оси «z»в поперечном движению магнитнолевитационного транспорта направлении.

Магнитодвижущую силу линейного асинхронного двигателя с продольно-поперечным магнитным потоком с 
учетом особенностей конструкции его индуктора после ряда преобразований представим в виде двойного ряда Фурье

$$
F(x, z, t,)=\frac{8 \tau F_{m}}{\pi^{2} l} \sum_{n} \sum_{v} n_{l} \cos \left(\pi n \frac{z}{L}\right) v_{\kappa} e^{j(\omega t+2 \pi v x / 1)},
$$

где $\quad \mathrm{F}_{\mathrm{m}}-$ амплитуда первой гармоники МдС;

$\tau$ - полюсное деление ЛАД;

$n$ - целое, положительное, нечетное число - порядок гармонической составляющей МДС по оси «z»), где период первой гармоники составляет $2 L=4(a+b)$;

$a, b-$ размеры индуктора в поперечном направлении;

$v$ - любое целое число - порядок гармоники в направлении оси «(x);

$n_{n}-$ коэффициент, учитывающий распределение МДС в зоне лобовых частей обмотки.

Предложенный подход к определению распределения МДС позволяет свести реальные модели ЛАД с продольнопоперечным магнитным потоком со сложным строением магнитных систем индукторов к расчетным математическим, позволяющим рассчитывать магнитное поле ЛАД для комбинированных систем тяги и боковой стабилизации высокоскоростного магнитнолевитационного транспорта.

\section{Сведения об авторе:}

СОЛОМИН Андрей Владимирович

E-mail:vag@kaf.rgups.ru.

\section{Information about author:}

Andrey V. SOLOMIN

E-mail: vag@kaf.rgups.ru. 